\title{
La problemática inherente a la creación de un mamífero transgénico, concebido como una obra de arte
}

\author{
Transgenic mammal creation inherent \\ problems, conceived as an artwork
}

\author{
Diego Carrizosa Posada (Colombia) \\ Magister en Estética e Histótia del Arte \\ Institución Universitaria Politécnico Grancolombiano \\ diegocarrizosa@gmail.com
}

\section{Resumen}

En este artículo el lector encontrará la manera en que se desarrolló el proceso de creación de GPF Bunny, idea gestada por el artista de origen brasileño Eduardo Kak, la cual se desarrolló durante el año 2000, en el Instituto Nacional de Investigaciones sobre Agronomía, en Francia. Con el fin de explicar los conceptos de carácter científico que se dieron para que este proyecto fuese realidad, se explicarán instancias inherentes a la ingeniería molecular como: proteína verde fluorescente, organismo genéticamente modificado, organismos vivos transgénicos y las razones científicas que justifican este tipo de experi-

\section{Abstract}

In this article, the reader will find out how GPF Bunny creation process was developed, developed by Brazilian origin artist Eduardo Kak, developed during 2000 in the National Institute of Agronomy Research, in France. In order to explain the scientific nature concepts that were given to become this project a reality, inherent instances to molecular engineering will be explained, such as: green fluorescent protein, genetically modified organism, transgenic living organisms and scientific reasons that justify this kind of experimentation,
Recibido:

Evaluado:

Aceptado:
17 de enero de 2017

16 de julio de 2017

4 de septiembre de 2017
PARA CITAR ESTE ARTÍCULO/TO CITE THIS ARTICLE

Carrizosa Posada, D. (2017). La problemática inherente a la creación de un mamífero transgénico, concebido como una obra de arte, Poliantea 13(24), p 155-174. 
mentación, las regulaciones que afectan la creación de seres transgénicos vivos, así como la opción de tener potestad sobre dichos individuos personas no vinculadas a la ciencia. Además, en este texto se reflexiona sobre lo biotecnología, el bio arte, y el arte transgénico, a partir de reflexiones sobre conceptos y ejemplos que hablan acerca de poder del hombre para imitar, interpretar y modificar la naturaleza. Se estudia sobre la autoridad que poseen los laboratorios de biotecnología para crear organismos transgénicos vivos amparados bajo razones de investigación médica, versus el paradigma que rodea a los artistas plásticos cuando se involucran en procesos similares de experimentación. Se diserta sobre la posibilidad que la creación de un organismo transgénico pueda ser parte de un proceso de evolución. Se plantea además una nueva teoría filosófica que habla de un existencialismo evolutivo, cuyas nociones pueden coadyuvar a la posible creación de un código de valores que regule los procedimientos genéticos de manipulación susceptibles de ser realizados en los seres vivos por parte de artistas. Se hace mención a la teoría de Michel Foucault, que habla de la estética de la existencia, que significa el derecho que posee cada individuo para realizar su proceso individual de estetización. Para concluir el lector conocerá las diferentes posturas tanto científicas, humanísticas y artísticas que tratan sobre la problemática que se presenta al romper con las diferencias naturales que separan las especies. Puesto que bajo nociones ya establecidas que se refieren a la evolución, es el interés de algunos comprender y modificar el fenómeno de la vida tal como es, probablemente sin percatarse realmente a fondo sobre las consecuencias que estos actos pueden provocar en el normal desarrollo del ciclo de la vida.

Palabras Clave: GFP Bunny, Eduardo Kac, biotecnología, bio arte y arte transgénico. regulations that affect the creation of living transgenic beings and the option of being owned by people not linked to science. In addition, this text reflects on biotechnology, bio art, and transgenic art, based on reflections on concepts and examples that speak about the power of man to imitate, interpret and modify nature. Is studied the power of biotechnology laboratories to create living transgenic organisms covered by medical research, versus the paradigm surrounding plastic artists when they engage in similar activities of life creation. It is discussed the possibility that the creation of a transgenic organism can be part of a process of evolution. There is also a new philosophical theory that speaks of an evolutionary existentialism, whose notions can contribute to the possible creation of a code of values that regulates the genetic procedures of manipulation that can be performed in living beings by artists. Mention is made of Michel Foucault's theory, which speaks of the aesthetics of existence, which means the right of each individual to carry out his individual process of aesthetization. To conclude the reader will know the different scientific, humanistic and artistic positions that deal with the problematic that is presented when breaking with the natural differences that separate the species. Since under established notions concerning evolution, it is the interest of some to understand and modify the phenomenon of life as it is, probably without really noticing in depth the consequences that these acts can cause in the normal development of the cycle of the life.

Keywords: GFP Bunny Eduardo Kac, biotechnology, bio art and transgenic art. 


\section{Introducción}

A manera de introducción se considera pertinente conocer en qué consistió la creación del proyecto GPF Bunny ${ }^{1}$, por parte del ingeniero químico LuisMarie de Houdebine PhD, con la colaboración científica de Patrick Pruntet, del artista brasileño Eduardo Kak, y con la asesoría de Luis Bec, especialista en procedimientos de evolución biológica.

Según Kak, (2007), en abril 29 del año 2000, en el Instituto Nacional de Investigaciones sobre Agronomía INRA, el cual se encuentra localizado en Jouyen-Joses, Yvelines, Francia, nacío una coneja en perfecto estado de salud. Dentro de las características fisiológicas del mamífero se destacaron el color de pelo blanco, los ojos rosados, y su piel sin pigmento.

Sin embargo, este mamífero contó con una especifidad, cuando se le expuso en total oscuridad a una luz ultravioleta de $488 \mathrm{~nm}$., presentó un nivel de fluorencia de color verde de una intensidad de 509 $\mathrm{nm}$. Vale la pena subrayar, que en condiciones normales de luz, su fluorencia de color verde no se puede apreciar, y que este brillo es emitido principalmente a traves la piel del cuerpo, de las orejas, de los ojos, y no por medio del pelo del mamífero.

El trabajo de ingeniería molecular consistió en crear una secuencia genética que fuera responsable de la producción de una proteina verde fluorecente, la cual fue obtenida de la medusa Aequorea Victoria. Una vez el gene portador de la fluorecencia fue integrado al genoma del mamífero por medio de una inyección al zygote, se produjo como resultado (bajo condiciones especiales de iluminación) una fluorencia de color verde. Se considera necesario aclarar, en razón al bienestar del mamífero, que este tipo de procedimiento es inofensivo para el especímen.

El termino en inglés utilizado para identificar este tipo de proteina es GPF: Green Fluorecent Protein, de allí nace el nombre del proyecto (GFP Bunny). Este

\footnotetext{
${ }^{1}$ Ver figura 1.
} 
tipo de individuo se identifica como un organismo genéticamente modificado. Esta categoría aplica a cualquier tipo de ser viviente que haya sido alterado utilizando técnicas de ingeniería genética. Obtenida el 7 de enero de 2017, de https://en.wikipedia.org/wiki/Green _fluorescent_protein. Se trata entonces de un ser que no existe en la naturaleza, que se conoce como quimérico, y que se encuentra connotado dentro del sentido de una tradición cultural de animales imaginarios.

El Protocolo de Cartagena en Bioseguridad, cuya legislación se encarga de regular el intercambio científico y el comercio internacional de OGMs (Organismos - vivos- genéticamente modificados), denomina de manera específica como organismos transgénicos, a los individuos cuyo mapa genético ha sido alterado por la adición de material genético de otro organismo no relacionado, mediante el uso de modernas técnicas en biotecnología. Obtenida el 7 de enero de 2017, de https://en.wikipedia.org/wiki/Genetically_modified_organism

¿Pero con que objetivo científico se crean organismos transgénicos vivos, como puede ser el caso de los mamíferos? Los doctores Ralph L. Blinster y Richard Palmiter, desarrollaron a comienzos de la década de los años ochenta las primeras técnicas de ingeniería genética para crear organismos vivos transgénicos como ratones, conejos, ovejas y cerdos. En un principio, estos procesos tomaban demasiado tiempo en ser desarrollados y tenían un costo muy alto, sin embargo hoy en día gracias a las modernas técnicas desarrolladas, las modificaciones genéticas son más económicas y más precisas.

Las razones científicas por las cuales se crean organismos transgénicos vivos corresponden a seis instancias: 1. Para investigar cómo prevenir algunas enfermedades que afectan al ser humano. La proteína verde fluorescente (GFP, por sus siglas en inglés), ha sido utilizada en los cerdos para estudiar problemas de incompatibilidad en procedimientos de trasplantes de órganos humanos. En el área de los felinos, un equipo de científicos de Japón y EE.UU, desarrollaron gatos fluorescentes para investigar terapias para curar el sida y otro tipo de enfermedades como el virus de la inmunodeficiencia felina. 2. Para producir productos industriales o de consumo, como es el caso de la fibras. 3. Para crear elementos farmacéuticos de uso terapéutico, como tejidos para implantes. 4. Para mejorar la interacción entre los humanos y sus mascotas, como por ejemplo, la creación de mamíferos hipo alergénicos. 5. Para mejorar el proceso de digestión de algunos mamíferos, como el cerdo. 6. Para mejorar la salud de los animales, con el objeto de fortalecer su resistencia a las enfermedades. Obtenida el 7 de enero de 2017, de https://en.wikipedia.org/wiki/Genetically_modified_organism

¿Quién descubrió la proteína verde fluorescente (GFP)? Fue el japonés Osamo Shimonura en 1962, cuando estudió el fenómeno lumínico producido por la anémona Aequorea Victoria. El científico nipón obtuvo su doctorado en química orgánica en la Universidad de 
Nagoya en 1962, posteriormente en el año de 2008, en conjunto con los científicos norteamericanos Martin Chalfie y Roger Tsien, fue galardonado con el Premio Nobel de Química, por las investigaciones realizadas en torno a la aplicación de la proteína verde fluorescente para propósitos de investigación médica. Hoy en día esta proteína, entre otras aplicaciones, se utiliza para investigar la prevención del cáncer, pues una vez es suministrada al individuo, permite aislar bacterias, células y virus, permitiendo su observación. Obtenida el 7 de enero de 2017, de http://www.agenciasinc.es/Noticias/Premio-Nobel-de-Quimica-2008-paralos-descubridores-de-la-proteinafluorescente-GFP

¿Qué tipo de regulaciones legales existen en EE.UU. y Europa, en torno al desarrollo de investigaciones de ingeniería genética que den como resultado la creación de organismos vivos transgénicos, como puede ser el caso de un ser humano a quien se le haya implantado la proteína verde fluorescente, individuo que se puede identificar como una quimera humano - animal?

Antes de dar inicio a la respuesta se considera pertinente aclarar que se encuentra científicamente probado la proteína en cuestión es totalmente inofensiva para la salud del ser humano, y que en la actualidad es posible realizar este tipo de organismo géticamente modificado. Obtenida el 7 de enero de 2017, de https://en.wikipedia.org/wiki/Genetically_modified_organism.

En lo que se refiere a la legislación norteamericana, en septiembre 22 de 2016, mediante el artículo H.R. 6131, que modificó el título 18 de código de los EE.UU, se prohibió tajantemente la creación de quimeras humano - animal. En Europa, existen estrictos códigos legales y éticos en torno a la prohibición de experimentación por medio de células humanas. En los demás países del planeta se presentan diferente tipo de regulaciones sobre el tema de organismos genéticamente modificados. Obtenida el 7 de enero de 2017, de https://www.congress.gov/bill/114thcongress/house-bill/6131/text

¿En qué consiste la reglamentación jurídica que trata sobre el tema de permitir la salida al exterior de un laboratorio de investigación de un organismo vivo genéticamente modificado? Las regulaciones varían de país a país, por ejemplo en el Reino Unido, es posible crear quimeras con células humanas, pero los embriones deben ser destruidos a los 14 días de nacidos. Por lo demás existe un consenso científico a nivel mundial, que no permite la salida de los laboratorios de organismos vivos genéticamente modificados, parte en razón por el potencial riesgo para la salud del ser humano al ser afectado por enfermedades de tipo zoonótico. Obtenida el 7 de enero de 2017, de https://en.wikipedia.org/wiki/Genetically_modified_organism

¿Para la venta pública existen hoy en día mascotas transgénicas fluorescentes? Los investigadores han desarrollado diversos individuos con las características que plantea la pregunta, como es el caso de peces, primates y perros, en- 
tre otras especies con propósitos exclusivos de investigación médica. Sin embargo, en el año de 2003 salió a la venta en el estado de California (EE.UU.), la especie pez cebra fluorescente en diferentes colores, bajo el nombre de GloFish. Esta variedad es distribuida por la empresa York Town Technologies, quien es poseedora de los derechos mundiales de comercialización. Su distribución al público norteamericano fue aprobada en el año 2003 por la Agencia Federal de Drogas y Alimentos (FDA, por sus siglas en inglés), después de dos años de investigaciones en los que se comprobó que el GloFish, era inofensivo para el ser humano. Obtenida el 7 de enero de 2017, de https://en.wikipedia.org/wiki/GloFish

¿Cuáles eran las intenciones de Eduardo Kak con GPF Bunny, una vez le fuese entregado por parte del Dr. Houdebine y del INRA? Kak deseaba presentar a la coneja fluorecente Alba -que fue el nombre que le otorgó Kak a GPF Bunny-, una vez se integrara al mundo exterior, como una creación artística viviente en una exposición de arte de la ciudad francesa de Avignon. Desafortunadamente para Kak, el director general del INRA no permitió la salida de Alba por fuera del INRA. Probablemente se conjugaron tres argumentos para que esta decisión fuese tomada, primero, que el experimento se realizó con fondos públicos franceses, por ende la coneja pertenece al Estado francés, en segunda instancia se pudo tener en cuenta el consenso científico mundial que no permite la salida al exterior de un laboratorio de investigación de un organismo genéticamente modificado, aun cuando ya para ese momento se había comprobado que
Alba no presentaba riesgo alguno para la salud humana.

La tercera hipótesis pudo radicar en una problemática sobre el crédito de autoría del proyecto. La idea de crear GPF Bunny pertence a Kak (2007), como el mismo artista lo afirma, sin embargo Houdebine sostiene que él nunca hubiera aceptado hacer realidad este proyecto para que un artista tuviera potestad sobre el mismo, sino con fines eminentemente científicos en pro de investigaciones que evitaran el desarrollo de enfermedades en el ser humano. La polémica no fue dirimida, y por ende el crédito de la autoría del proyecto nunca fue aclarado, y Alba continuó su vida como sujeto de investigación en el INRA.

En consecuencia, el segundo objetivo de Kak que consistía mantener a la coneja Alba como mascota, y bajo una connotación de obra de arte en su residencia tampoco fue logrado. Kak no contento con la decisión realizó gran cantidad de actos públicos en radio, prensa y televisión a nivel mundial, mediatizando la creación de Alba como una obra de arte viviente que le debería ser devuelta, con el objetivo de ser dada a conocer en los entornos artísticos.

Kak (2007), continuó con sus esfuerzos para lograr que Alba le fuese entregada, por tal razón, en el año 2002 realizó una exhibición individual en la galería de arte Julia Friedman Gallery de Chicago, que se tituló: Free Alba, (Liberen a Alba). El evento consistió en la introducción de material impreso con la imagen de Alba, el cual se pre- 
sentó en soportes como fotografías a color de gran escala, dibujos, banderas y camisetas. Se trataba de fortalecer con el público asistente la campaña de liberación de Alba.

Alba jamás fue entregada a Kak, como tampoco fue dada a conocer de manera pública. Aproximadamente un par de años después de la concepción de Alba, el Dr. Houdebine informó la comunidad científica que Alba había muerto por causas naturales, dando fin a esta polémica. Obtenida el 7 de enero de 2017, de http://archive.wired.com/medtech/ health/news/2002/08/54399?current Page $=$ all

En virtud de lo anterior, el objetivo de este trabajo es responder a la siguiente problemática ¿En el contexto de los inicios del siglo XXI, desde las instancias artísticas, científicas, filosóficas y evolutivas, que conceptos se desprenden de la creación de GPF Bunny en el año 2000.

De acuerdo con lo anteriormente planteado, se considera importante conocer quiénes son, y/o cual es la línea de trabajo y de pensamiento de las tres principales personas directamente involucradas en la creación de GPF Bunny.

Eduardo Kak nace en Río de Janeiro, Brasil en el año de 1962, es graduado de la Facultad de Comunicación Social de la Pontificia Universidad Católica do Rio de Janeiro. Su obra es reconocida internacionalmente por sus instalaciones interactivas, así como por sus realizaciones en el campo del arte biotec- nológico. Su búsqueda tiene como objetivo conocer los vínculos entre lo físico y lo virtual, así como entre las instancias biológicas y tecnológicas. Su razón de estudio radica en la ruptura de los límites fijados por la naturaleza, con el objeto de cuestionar las nociones de evolución. Dentro de sus obras se destacan, Génesis 1999, GFP Bunny, 2000, El octavo día, 2001, La historia natural del enigma, 2003-2008, Especímenes de secreto acerca de descubrimientos maravillosos, 2004-2005, Movimiento 36, 2004-2006, entre otros más. Es profesor de seminarios de arte y tecnología en el Instituto de Arte de Chicago, en los Estados Unidos, institución de donde obtiene un grado de maestría en Artes Finas. De sus publicaciones sobresalen Hodibis Potax, Ed. Action Poétique, París, 2007. Poesía de los medios: Una antología internacional $\mathrm{Ed}$. Intellect Books, Bristol, 2007 y Vida extrema, Ed. Dis Voir, Paris, 2007.

Sobre la línea de trabajo del ingeniero químico de origen francés Luis-Marie de Houdebine $\mathrm{PhD}$, quien fuese el experto científico a cargo del proyecto GPF Bunny, se puede mencionar lo siguiente. Es el director del Departamento de Estudios Genéticos sobre la vida animal en el INRA, (Instituto Nacional de Investigaciones sobre Agronomía), y es miembro de la Comisión Francesa de Genetistas. Houdebine es mundialmente reconocido como uno de los grandes especialistas el tema de la recombinación de las proteínas de la leche, obtenida de animales transgénicos. Obtenida el 7 de enero de 2017, de http://www.bloomberg.com/research/ stocks/private/person.asp? 
Acerca de Louis Bec, quien se desempeñó como asesor especialista en procedimientos de evolución biológica en la creación de GPF Bunny, sobresalen las siguientes instancias. Dentro de sus actividades como escritor y artista, es muy conocido en Europa como creador del arte literal de la vida. Bec (2007), menciona que por medio de la intervención directa en el genoma de los vivos, el arte biotecnológico podría producir con la ayuda de genetistas, constructos- o sea organismos vivos genéticamente transformados en que respondan de manera específica a tareas determinadas como también a ambiciosos objetivos poéticos.

\section{Estrategias metodológicas}

En este documento se trabaja bajo la teoría hermenéutica, con el método estructuralista, el cual se concentra en explicar, interpretar y comprender diferentes teorías expresadas en un determinado tiempo y espacio sociocultural. Cuyo objetivo se concentra en proveer desde la interdisciplinariedad, diferentes puntos de vista con el propósito de obtener una explicación interpretativa a la problemática planteada. De acuerdo con lo anterior son consultadas las nociones expresadas por parte de autores reconocidos en el tratamiento de los siguientes temas: Michel Foucault (la estética de la existencia), Louis Bec, (el diseño de seres fantásticos de la naturaleza), Cary Wolfe (la bioética desde la filosofía), Lory Andrews, (implicaciones éticas y legales de la creación de organismos transgénicos), Dominique Lester (la bioética y la estética), Yves Michaud (el arte biotecnológico) y Eduardo Kak, (la transformación de la vida).

\section{Connotaciones en torno a la biotecnología y el bioarte}

A continuación se razona pertinente explicar el significado de unas palabras que se consideran importantes para contextualizar el contenido de este artículo, se trata de biotecnología y bio arte. Según Michaud, (2007), el primer término se aplica a designar instrumentos biológicos, o herramientas mediante las cuales se pueden producir ciertas sustancias, seres vivos, o procesos biológicos que podrán ser utilizados en procedimientos técnicos. La biotecnología, es una técnica que utiliza organismos vivos, o partes de organismos vivos con el objetivo de producir o modificar objetos, mejorar las plantas o los animales, desarrollar microrganismos, o llevar a cabo realizaciones de naturaleza biológica. Las biotecnologías cubren una gran variedad de procedimientos, desde los considerados tradicionales y ancestrales, hasta las más recientes aplicaciones de naturaleza bioquímica y genética. Dentro de la anterior clasificación se distinguen las técnicas de fermentación, para hacer quesos y bebidas alcohólicas, técnicas para preservar la conservación y evitar el envejecimiento en el ser humano, para mejorar la calidad de los campos de cultivo, para domesticar animales y mejorar razas, para producir cruces entre animales y vegetales, obteniendo como resultado nuevos híbridos entre los reinos vegetal y animal. Todo esto hace parte de la biotecnología y ya sucediendo en la actualidad. 
En lo que se refiere al área del arte visual y la biotecnología, en virtud de Michaud, (2007), la humanidad ha trabajado en realizar tatuajes, escarificaciones, e implantes, todos estos procedimientos han mejorado recientemente mediante los avances de la cirugía estética. También en el área del arte de los jardines, en Holanda desde el siglo XVII se ha trabajado en el mejoramiento de la calidad de los tulipanes, así como en el Asia continúa la tradición del cultivo de los peces ornamentales, procedimientos que han sido afectados en igual manera por los avances de la genética biotecnológica. Si se realiza una referencia a la teoría de Aristóteles, que habla acerca del arte como un instrumento que logra lo que la naturaleza no puede conseguir, entonces las biotecnologías, se han constituido desde hace tiempo como una parte integral de los recursos utilizados por el arte, aportando para su desarrollo evolutivo nuevas prácticas.

De acuerdo con Kak (2007), a partir de la unión del arte y la biotecnología, nace el bio arte, que se convierte en una nueva tendencia en el arte contemporáneo, que manipula el proceso de la vida. Se trata de un invento o transformación de organismos vivos, que se encuentran integrados o no, a un ambiente específico para su desarrollo de vida. Dentro de un entorno orgánico, el sentido del bio arte propone a partir del uso de las propiedades de la vida y de sus materiales, la modificación de organismos vivos dentro de su propia especie, y se reserva el derecho de inventar la vida bajo nuevas características. Situación de la que se desprende de manera teórica, que muchos de estos trabajos artísticos de naturaleza biológica, podrían existir en el planeta, por la misma cantidad de tiempo que exista la vida, teniendo en cuenta que sean capaces de reproducirse bajo formas naturales o artificiales.

Kak (2007), declara que lo que connota al bio arte como único, es que no se compara o relaciona con otras formas, como por ejemplo con el arte ecológico, pues se enfoca fundamentalmente en los procesos de la vida y de la genética. El bio arte debe ser diferenciado del arte que utiliza medios tradicionales o digitales para referirse a temas de naturaleza biológica, como pintar o realizar una escultura que refleje la forma de un cromosoma, u obtener una fotografía digital que sugiera la imagen de dos niños clonados, puesto que el bio arte, como su nombre lo indica se realiza sobre organismos vivos. Además, dentro de su especifidad, el bio arte, no puede ser clasificado dentro de los ready made, el arte conceptual, el situacionismo, o la escultura social, concepto que se desprende una afirmación propuesta por Joseph Beuys en 1979, que planeaba que cualquier persona podía ser un artista, por lo que todos deberían participar en el proceso de moldear el mundo. El bio arte también se diferencia del conceptualismo, el cual dentro de sus postulados busca fortalecer el uso de las ideas, del lenguaje, así como de la documentación de eventos.

Kak (2007) sostiene además que el bio arte entonces enfatiza sobre los diálogos relacionales, como por ejemplo la polinización, las relaciones sociales, la interacción celular y la comunicación entre la diferentes especies, como puede ser la forma del cuerpo de las ranas, el color de 
las flores, la bio luminiscencia, y los patrones de las alas de las mariposas.

Kak (2007) en torno a las diferencias que se pueden establecer entre el bio arte en lo general, y el arte transgénico en lo particular, asevera que el primero corresponde a la creación de nueva vida, y que el segundo consiste en la manipulación de material biológico de manera discreta, en lo que tiene que ver con las células, proteínas, genes y nucleótidos.

\section{El poder del hombre para repre- sentar y modificar la naturaleza vegetal, animal y humana con propósitos artísticos}

Kak (2007) manifiesta que la presencia de organismos vivos en el arte ha estado presente desde comienzos del siglo $\mathrm{XX}$, es así como los animales y las plantas han sido utilizadas por los artistas de variadas maneras para expresar sus objetivos plásticos. Que mientras el arte moderno y contemporáneo ha producido objetos, (pintura, escultura y ready mades), el arte de los entornos ha producido, (instalaciones y land art), el arte de los eventos ha producido, (performances y happenings), y el arte de los trabajos inmateriales ha producido, (video, piezas digitales, así como sitios web), el bio arte se ha encargado dentro de su núcleo central de producción, el realizar trabajos de desarrollo de organismos (ontogenia) y de evolución de especies (filogenia). De allí que se abre a una entera gama de investigación sobre el desarrollo de entidades y proce- sos de vida, que van desde moléculas de $\mathrm{ADN}$, los virus más pequeños, hasta el desarrollo de los grandes mamíferos y su linaje evolutivo.

Sobre la concepción de las representaciones de los rostros humanos mediante la armoniosa selección de frutas, flores y vegetales que representan plantas humanas, en el siglo XVI, sobresale la obra plástica del artista italiano manierista Guiseppe Arcimboldo (1527-1593), quién ofrece visiones sorprendentes de imaginación biomórfica, como es el caso de su obra, Vertummus ${ }^{2}$ (ca.1590), en la que aparece representado el rostro de Rodolfo II, en la manera del dios romano de la vegetación y de la transformación. Esta propuesta de gran imaginación de Arcimboldo, contribuyó a vislumbrar hasta donde podía llegar el alcance del arte (Kak, 2007).

En lo que se refiere a la utilización de una mamífero en el campo del arte, el primer evento del que se tiene noticia y que causó una gran impresión tuvo lugar en el café Lapin Agile o Conejo Ágil (por su traducción del francés), uno de los sitios favoritos de Picasso, localizado en el barrio bohemio de Montmartre, en París. En 1910, el crítico de arte Roland Dorgelès se le ocurrió amarrarle un pincel a la cola de un burro - una mascota muy querida por los asistentes al café, llamada Lolo $^{3}-$, de propiedad del cantante Frédé. Una vez se le daba comida al mamífero, este movía la cola con gran alegría, y mientras tanto Dorgelès sostenía un lienzo en blanco y lo acomodaba frente a la cola del burro, como

\footnotetext{
2 ver figura 2.

3 ver figura 3 .
} 
resultado de los movimientos y de los cambios en los colores de la pintura resultó una obra pictórica, que se tituló Y el sol se quedó dormido sobre el Adriático ${ }^{4}$. Este trabajo fue presentado en el Salón de los Independientes de París, bajo el seudónimo de JoachimRaphaël Boronali, y tuvo gran acogida, pues en el catálogo que acompañaba la pieza, Dorgelés escribió que pertenecía a la tendencia artística de Excesivo movimiento, la obra fue vendida por 400 francos y Lolo entró a la historia del arte, no sin antes explicar a los jurados del Salón que se trataba de una broma. Obtenida el 11 de enero de 2017, de https://bonjourparis.com/archives/cafelapin-agile-montmartre-lolo-infamousart-hoax/. En este caso se trató de la colaboración entre un experto en arte y un animal, situación en la que el mamífero sustituyó al hombre en la realización de un objeto con connotaciones artísticas.

Dentro de los artistas que se destacan por plantear en su obra imágenes de gran libertad de imaginación, se encuentra Jusepe de Rivera, (Ca.15901652), pintor y grabador español del siglo XVII, quien representa en la pintura titulada: La mujer barbuda ${ }^{5}$ de 1631, a Magdalena Ventura, quien en la imagen representada aparece a la edad de 37 años, con barba, dándole pecho a un niño que acaba de nacer. También sobresale Lavinia Fontana (15521614), pintora italiana del primer barroco, quien representa a una niña con el rostro cubierto por pelo ${ }^{6}$, en su obra Retrato de una niña cubierta de pelo5(ca.
1594-1595). Las dos figuras exhibidas con dignidad, presentan conjuntamente visiones que se remontan a un tipo de normatividad biológica, que consiste en un síndrome hormonal, que causa exceso de crecimiento del pelo. Este tipo de trabajos que representaban dos ejemplos de fenotipo androgénico, contribuyeron a estrechar el canon visual de la época, más allá del estándar biológico (Kak, 2007).

Más adelante en el tiempo, estos trabajos han servido de inspiración a otros aún más arriesgados, como es el caso del trabajo del surrealista belga, Rene Magritte, (1898-1967), La invención colectiva ${ }^{7}$ de 1935, en el que se observa un ejemplo de una transformación morfológica, que representa una figura compuesta por un segmento de un medio cuerpo de una mujer desnuda de los pies hasta la cintura, cuya parte superior remata con la figura de un pez, representado desde la parte media de su envergadura hasta la cabeza. Esta obra de anatomía recombinada, se convirtió en una señal de la manera en artistas del siglo XX trabajaban de manera incesante, por fuera de los límites del cuerpo humano y de los principios de la biología (Kak, 2007).

Curiosamente, un año después de la exhibición pública de la quimera de características inversas de Magritte, Edward Steichen, pintor, fotógrafo, promotor del arte moderno y horticultor (18791973), se convierte en el primer artista que crea nuevos organismos mediante

\footnotetext{
${ }^{4}$ ver figura 4.

5 ver figura 5.

${ }^{6}$ ver figura 6.

${ }^{7}$ ver figura 7 .
} 
métodos tradicionales y científicos, así como en la primera persona en exponer este tipo de arte en un museo. Fue así como en el año de 1939, se presentó Delphiniums $^{8}$ en el MoMA, materializándose como la primera creación de origen vegetal que probaba que la genética puede tratarse de un medio artístico. (Kak, 2007).

En el año de 1974, el artista alemán Joseph Beuys realizó el performance Me gusta América y a América le gusto $\mathrm{yo}^{9}$, en la cual involucraba la presencia de un coyote salvaje vivo. En el espacio de la Galería Rene Block de Nueva York, Beuys se encierra con el depredador durante tres días, separado del público mediante una reja metálica. El objetivo de la obra consistía en realizar un diálogo con el mamífero, el cual involucraba la acción del ofrecimiento de diferentes elementos como es el caso de una tela de fieltro, unos guantes, y una linterna que el coyote tocaba con sus patas. Beuys enfatizó que el animal le otorgó al artista entre otros aspectos la posibilidad de conocer el trauma del conflicto americano con el indio. Obtenida el 11 de enero de 2017, de http://1.bp.blogspot.com/s1600h/fotojbeuysd.jpg. En así como mediante este performance de tipo político, Beuys manipuló con propósitos estéticos el comportamiento del animal mediante la representación de su encierro y convivencia con un ser humano, connotando de esta manera al hombre y al mamífero como obras de arte.

\footnotetext{
${ }^{8}$ ver figura 8 .

${ }^{9}$ ver figura 9.

${ }^{10}$ ver figura 10.
}

Un artista que se destaca trabajando dentro del área arte visual y del bio arte, utilizando la ciencia como base de sus creaciones artísticas, es Louis Bec, (1936). Bec, quien es de origen francés, se ha concentrado en simular nuevas formas de vida, mediante procedimientos de extensión de evolución biológica, como es el caso de Prolegomena ${ }^{10}$ de 1993. Este artista mediante la creación nuevos especímenes de tipo zoomórfico, busca fortalecer los procesos de evolución de este tipo de especies. (Kak, 2007).

Es así como se puede observar que las realizaciones artísticas que tuvieron lugar en el siglo XX, y que se relacionaron con especies vivas del reino vegetal $y$ animal, así como con el hombre, pudieron haber planteado nuevos horizontes que coadyuvaran al desarrollo del arte transgénico.

\section{Se puede considerar como po- testad exclusiva de los labo- ratorios, el manipular organis- mos vivos con intenciones de crear seres transgénicos por ra- zones de investigación médica, y no bajo un objetivo de con- notaciones estéticas, como es el caso de la obra de un artista?}

Dominique Lester (2007) sostiene que el hombre potencialmente puede hacer cualquier cosa, sin embargo esa 
supuesta libertad radica en lo que realmente se encuentra autorizado para poder hacer. No hay que olvidar que el proceso de transformación de organismos vivos con fines médicos ha sido cuestionado en algunos casos, pero por lo general, mediante elaboradas argumentaciones científicas, prácticas específicas non sanctas han sido aceptadas Si se plantea la pregunta que atañe a, ¿̇si los humanos tienen el derecho de manipular la vida animal por propósitos médicos?, se pueden dar dos tipos de respuesta, la primera tiene que ver con los derechos de los animales, puesto que tanto su vida, como desarrollo deben tener lugar en un ambiente natural, razón por la cual, el hombre no tiene el derecho a interferir o modificar tal situación. La segunda consiste en que a los animales no se les debe hacer sufrir ni física, ni psicológicamente durante los procesos de experimentación, situación que puede suceder en algunos casos. La siguiente pregunta se refiere a la manipulación de los animales con propósitos estéticos, la argumentación en contra de tal interrogante se refiere a los derechos de los animales a no ser manipulados, la posición a favor radica en que por medio de la intervención estética el hombre le otorga la posibilidad al animal de obtener un lugar y una característica especial dentro del mundo de los vivos. La manipulación estética de los organismos vivos realizada por humanos, puede connotarse como una perversa invención de tipo cultural, sin embargo se trata de una tendencia básica e inherente a la evolución de los organismos vivientes. Como por ejemplo, algunas especies de cangrejos araña adoptan la costumbre de seleccionar elementos de su entorno natural como algas, espon- jas, briozoos (animales tipo musgo), y ascidias (conocidas bajo el nombre vulgar de chorros marinos), para realizar guirnaldas las cuales son colocadas por ellos en diferentes partes del caparazón. Muchas especies de cangrejos decoradores existen en la naturaleza, se decoran durante toda su vida, y sus parámetros estéticos de decoración varían de especie a especie, esta situación atrae la atención visual de otros cangrejos, así como de otras especies. ¿Pueden estas actitudes de comportamiento funcional animal ser interpretadas como estéticas bajo parámetros humanos? Una posible respuesta puede radicar en que la interpretación del concepto de lo estético por parte de los humanos, no puede dar luz a una interpretación sobre lo que los animales consideran como estético, pero que por alguna razón de la naturaleza, la acción de los cangrejos araña se da como resultado de un comportamiento de tipo estético, que tiene lugar cuando el sentimiento del otro es manipulado, y el placer es despertado. Desde el neolíitico, los humanos han buscado de manera consciente manipular la vida, no solo por razones materiales, sino por razones de placer visual, como es el caso de diseñar los más bellos animales, -por argumentos de tipo emocional-, la creación de animales con grandes características afectivas, -por razones emocionales, así como la realización de animales que posean una gran carga simbólica. Esta clase de experimentación en animales refleja modificaciones de tipo anatómico, de comportamiento y de tipo cognitivo. En otras palabras las manipulaciones de la vida animal con propósitos estéticos, realizadas por parte de los artistas siempre contienen un especial significado. En virtud de lo ante- 
riormente expresado, se puede afirmar que en la historia de la vida del ser humano se tiene la posibilidad de navegar entre dos posibilidades, la racionalidad instrumental (que se encarga de movilizar los medios y las esperanzas para lograr un objetivo particular) y la racionalidad expresiva (que mueve los medios y la esperanza para obtener una expresión de tipo individual).

Lory B. Andrews (2007), manifiesta que aprecia a los artistas cuyo trabajo se encuentra influenciado por las ciencias biológicas, porque más allá del valor estético de sus obras, su trabajo puede coadyuvar a la sociedad para: confrontar las implicaciones sociales que resultan de sus elecciones dentro del campo de la biología, comprender las limitaciones que surgen de los avanzados desarrollos logrados en el campo de la biotecnología, para desarrollar políticas públicas que se encarguen de regular esos avances, y por último, confrontar los grandes temas del papel que juega la ciencia, así como el rol del arte en nuestra sociedad.

\section{¿Puede ser considerado como parte de un proceso evolutivo, la creación de un organismo transgénico?}

De acuerdo con Dominique Lester (2007) en términos de evolución la inmovilidad es una forma de suicidio pasivo. En virtud de los biólogos, la teoría de Darwin que habla de la capacidad de adaptación y transformación de los seres vivos se constituye en una condición necesaria para que las especies puedan sobrevivir. En razón a la lógica darwiniana, los etólogos necesitan comprender el propósito que encierra un comportamiento inútil en un ser vivo, la razón para tal aseveración se encuentra en la siguiente noción, una característica que en un determinado momento se considera inútil, tiempo después puede ser necesaria para que una especie sobreviva. La manipulación de los seres vivos, por parte de los humanos puede ser considerada como una posición de tipo naturalista. Desde esta perspectiva, no solamente se considera ético manipular la vida, así estas manipulaciones tengan lugar dentro de la órbita de lo biotecnológico, pero no sería ético evitar que estas manipulaciones tuvieran lugar. El hecho que los humanos hacen parte integral del entorno en el que habitan los animales y le ofrecen a este reino las oportunidades para desarrollarse y cambiar, se considera poco ético congelar la vida en un sentido arcaico, en vez de ofrecer la posibilidad de transformarla, y por ende no permitir el acceso a los organismos vivos de posibilidades de renovación.

\section{El existencialismo evolutivo y su re- lación con la posibilidad de crear un código de valores que regule los procedimientos genéticos de manipu- lación suscetibles de ser realizados a los seres del reino animal por razones estéticas}

Dominique Lester (2007) explica de manera simplificada, que la teoría del existencialismo es la filosofía que habla del derecho que tienen los humanos sobre el control de su existencia, así como de su proceder. Se refiere en sus escritos de manera específica al existencialismo cristiano de Søren Kierkegaard, 
y al ateísmo existencialista de Jean-Paul Sartre, que hablan sobre la no existencia de Dios, por lo que los humanos no pueden ser definidos, ni medidos mediante preceptos de tipo religioso, sino por la suma y resultado de sus acciones. En virtud de la anterior mención filosófica, Lester (2007), propone una nueva teoría igual de ateísta que la propuesta por Sartre, que en este caso se refiere a una posición filosófica denominada existencialismo evolutivo, la cual se encuentra formulada bajo tres particularidades. Es evolutiva porque su órbita encierra la situación individual de un sujeto o de un grupo, así como a las especies. Es tecnológica, porque enfatiza el poder del individuo por medio de las nuevas tecnologías, que ofrecen a un sujeto novedosas acciones y oportunidades (cuyas consecuencias pueden ser positivas o negativas). Además, porque considera que cada ser viviente determina quién es (por cuanto el existencialismo se extiende al reino animal). De acuerdo con la teoría del existencialismo evolutivo, el ser humano debe asumir su destino, así como el de los organismos vivos en general. Uno se pregunta, iporque no dejar a los animales en paz?, porque realmente esa precisa alternativa no existe hoy en día, puesto que en estos tiempos de avanzados desarrollos en aspectos biotecnológicas es difícil no observar que la opción no recae únicamente en dejar el animal en paz, o manipularlo. Dentro de ese contexto, surge entonces la necesidad de crear un código de valores que regule los procedimientos genéticos de manipulación susceptibles de ser realizados en los seres vivos por razones estéticas, situación que se puede dar, de acuerdo con la legislación en bioética de algunos de los países de- sarrollados de Occidente. Es así como el tema de la bioética, y su relación con la personalización de animales por parte de los humanos, requiere redefinir una nueva normatividad para quienes lo practican, así como para todos los organismos vivos que son susceptibles de ser intervenidos.

\section{La estética de la existencia}

Kak (2007) se refiere a la noción de Foucault denominada, la estética de la existencia, que significa el derecho que tiene cada individuo para proceder con su proceso individual de estetización, el resultado de ese comportamiento estético, legitima una filosofía de la vida que prima sobre el sentido de lo científico. En otras palabras, la noción de la estética de la existencia, se comprende como una forma de vida acorde con los principios formales del uso de los placeres.

\section{Conclusiones}

\section{La salud del alba y su posible presen- cia en el exterior}

Eduardo Kak afirmó que durante el proceso de gestación de Alba, no se presentaron inconvenientes de tipo médico, que la coneja no sufrió durante la intervención, que nació con buena salud, que por ende no presentaba ningún riesgo para la salud humana y que presentaba características de gentileza. El objetivo del artista brasileño consistía en un total compromiso hacia el mamífero, en lo que se refería al respeto, a una correcta alimentación, y por encima de 
todo a otorgarle mucho amor. De acuerdo con los requerimientos de procedimiento científico, en lo que se refiere a la seguridad sanitaria era totalmente viable que a Kak le fuese entregada Alba, para su cuidado, desafortunadamente primaron otro tipo de argumentos, por lo que Alba le fue retenida en el INRA, hasta que murió.

\section{El objetivo de alba como obra de arte}

Como se ha mencionado la intensión de Kak con Alba contenía propósitos artísticos, al igual que de tipo hogareño, pues consideraba mantenerla como mascota en su casa de habitación. Alba posiblemente hubiese tenido crías de tipo transgénico, o sea una descendencia de conejos fluorescentes. Situación ideal en la que Kak podría haber realizado una instalación de arte, en la que probablemente se evocaría a Jannis Kounellys, que convirtió la galería de arte L'Aticco de Roma en un establo, para la presentación de su trabajo titulado Horses, que incluyó la presencia de doce caballos vivos.

La gran diferencia en torno a la realización del evento artístico de Kounellys que tuvo lugar en 1969 en la capital de Italia, y otro de similares características, que probablemente hubiese surgido de la imaginación de Kak -este caso se utiliza la especulación en para contextualizar una situación potencial -, que pudiese haber tenido lugar a finales del año 2000, y que hubiese contado con la presencia de un grupo de conejos transgénicos, el acto artístico se hubiese convertido en la presentación de una instalación de individuos conno- tados como obras de arte transgénico. Situación hipotética que le hubiese significado a Kak, un gran reconocimiento en el mundo artístico del momento, puesto que se hubiese tratado de la presentación pública de unos organismos vivos genéticamente modificados, cuya existencia era única dentro de la naturaleza.

\section{La imposibilidad que se le presenta los artistas par crear seres transgénicos con propósitos estéticos}

Hoy en día, los procedimientos científicos de tipo biotecnológico que se realizan en los institutos de investigación genética para crear o modificar seres transgénicos, ya sea dentro del área de la ciencia, cuyo objetivo redunda en beneficios para la salud humana, o con propósitos estéticos por parte de artistas, deben ser efectuados con gran cuidado, en razón a las posibles consecuencias que se pueden derivar de dichos actos.

Dentro del área de la ingeniería genética, debe exigirse mucha responsabilidad en el tema que se relaciona con la transmisión a los humanos de enfermedades de tipo zoonótico, y otras afecciones desconocidas por el ser humano, que puedan ser derivadas de experimentos de tipo transgénico, cuyas soluciones médicas posiblemente no se encuentran aún descubiertas. Sin embargo, hoy en día los principales laboratorios de investigación de ingeniería genética poseen departamentos que se encargan de estudiar temas relacionados con la bioética, instancia que pertenece a la rama de la filosofía. 
En el caso de las artes, se puede exponer como ejemplo una situación hipotética, en la que a un artista avant garde se le ocurre la posibilidad de dotar a un hijo suyo con la proteína verde fluorescente. Esta acción que se convierte en una situación muy tentadora para crear un happening en una galería de arte, se enfrenta a un hecho de grandes dimensiones estéticas, como también de duras repercusiones en lo ético, moral y legal.

En virtud de lo anterior, se considera necesario medir muy cuidadosamente las consecuencias que se presentan entre las necesidades de la ciencia y los propósitos estéticos, con el fin de ubicar si prima en el ser humano una racionalidad instrumental o una racionalidad expresiva, situación en la que es muy difícil encontrar una ecuanimidad.

\section{Las teorías evolutivas y filosóficas confluyen entre si}

Es un hecho que hoy en día es imposible impedir el avance de la ciencia, en lo que se refiere a la bioética contemporánea, por tal razón es vital la implementación de un código de valores que regule los procedimientos genéticos de manipulación que pueden ser realizados tanto en animales como en humanos. Los países más desarrollados se encuentran en capacidad de influir en la aplicación de este tipo de normatividad con el fin de prevenir la creación de seres transgénicos (tanto con propósitos científicos, como con objetivos artísticos), que posean características monstruosas, que transciendan todo tipo de parámetro que pueda afectar la salud pública, así como las normatividad que rige el desarrollo de la vida, como es el caso de las normas sociales, morales, y jurídicas.

De acuerdo con la teoría del existencialismo evolutivo, el ser humano debe asumir su destino, y el de los organismo vivos en general, dentro de los aspectos que comprenden dicha teoría como son la evolución, la tecnología, el poder de cada ser de determinar quién es. La teoría de la evolución de Darwin radica en la capacidad de adaptación y transformación de los seres vivos, como condición necesaria para su supervivencia, la tecnología ofrece la posibilidad de transformar la vida, otorgando a las especies posibilidades de renovación. Y el poder de determinación del ser humano debe coadyuvar a la implementación de un proceso de responsabilidad social en el que se busque evitar que transciendan por razones científicas o artísticas, creaciones transgénicas que afecten la ética, la moral y la belleza.

\section{Referencias}

Borges, J. L. \& Guerreo, M. (1969), The book of Imaginary Beings, New York: Dutton.

Cao, Vacanti J.P., Paige K. T., Upton, J., \& Vacanti, C. A. (1997). Transplantation of Chondrocytes Utilizing a Polymer-Cell Construct to Produce Tissue Engineered Cartilague in the Shape of a Human Ear, Plastic and Reconstructive Surgery Magazine, p. 297302.

Debord, G. (1967), The Society of the Spectacle. New York: Zone 
Books.

Fehilly, C.B., Willadsen, S.M., \& Tucker, E.M. (1984, February 1622) Interspecific Chimanerism Between Sheep and Goat, p. 634.

Foucault, M. (1997), The Birth of Biopolitics en: Michel Foucault: Ethics, The Essential Works, I Ed., London: Penguin.

Foucault, M., (1984), The History of Sexuality. Vol: 2. The Use of Pleasure. New York: Vintage Books.

Flusser, V. \& Bec, L. (1987), Vampyrotheuthis Infernalis: Eine Abhandlung samt befund des Institut Scientifique de Recherche Paranaturaliste Gottingen. Ed. European Photography.

Hanson, S. (1977), Kontextsound Catalogue, Amsterdam, Stedelijk Museum.

Horace, (2000), The art of Poetry, in: Classic Literary Criticism, London and New York: Penguin Books.

Kac, E. (Ed). (2007), Signs of Life. Bio Art and Beyond, Massachusetts, London: MIT Press.

Lester, Dominique. Arts and Biotechnology, en Signs of Life, Bio Art and Beyond, Cambridge, Massachusetts, The MIT Press, 2007.

Lewontin, Richad C. Biology as Ideology: The Doctrine of DNA. 1993. New York. Harper Perennial.

Margulis, Lynn. Symbiotic Planet: A new look at evolution. 1998. New York. Basic Books.
Maureau, de Maupertuis, Pierre Louis. 1768. Essai de Cosmologie; Systéme de la Nature; Reponse aux Objections de M. Diderot. 1984. Paris. Librarie Philosophique J. Vrin.

Mayer, Klauss et al. (1999, December 16) Sequence and Analysis of Chromosome 4 of the plant Arabidopsis Thaliana. Nature Magazine \# 402. (6763)

Maturana, Humberto. \& Varela, Francisco. Tree of Knowledge: The Biological Roots of Human Understanding. 1992. Boston. Shambala Publications.

Michaud, Ives. Arts and Biotechnology, en Signs of Life, Bio Art and Beyond, Cambridge, Massachusetts, The MIT Press, 2007.

Michaud, Yves. L'art a' l'e'tat gazeux, essai sur le triomphe de lesthe'tique. (2003). Paris. Ed. Stock.

O“ Brien, Patrick. Picasso: A Biography. 1994. New York. Norton.

Offray de La Mettrie, Julien. Man a Machine and Man a Plant (1994) Indianapolis. Ed. Hackett Pub. Co.

Of Hippo, Agustin. Against Julian. 1992. Washington D.C. Catholic University Press.

Richard Doyle, En: Beyond Living: Rhetorical Transformations of the Life Sciences (1997) Palo Alto. Ed. Stanford University Press. 
Rickaby, Joseph. Aquinas, Saint Thomas. En: That rational Creatures are governed by Providence for their own sakes. And other creatures in reference to them. 1905. London. Burns and Oates.

Steichen, Edward. ¡Delphinium, Delphinium and more Delphinium! (1949) Ed. The Garden March.

Kak, Eduardo. Art that looks You in the eye: Hybrids, Clones, Mutants, Synthetics, and Transgenics, en: Signs of Life, Bio Art and Beyond, Cambridge, Massachusetts, The MIT Press, 2007.

Kak, Eduardo. Hodibis Potax. 2007. París. Action Poétique.

Kak, Eduardo. Poesía de los medios: Una antología internacional. 2007. Bristol. Intellect Books.

Kak, Eduardo. Vida Extrema. 2007. Paris. Ed. Dis Voir,

Kosuth, Joseph. First Investigations. (Art as and Idea) 1966. Solomon, R. Guggenheim Museum. New York. Joseph Kosuth/ Artists Rights Society.

Kropotkin, Peter. Mutual Aid: A factor of evolution. 1989. Montreal. Black Rose Books.

Varela, Francisco \& Thompson, Evan. \& Rosch, Eleanor. 1991. The Embodied Mind: Cognitive Science and Human Experience. Cambridge. MIT Press.

Wolfe, Cary. Arts and Biotechnology, en Signs of Life, Bio Art and Beyond, Cambridge, Massachusetts, The MIT Press, 2007.

Xiaoying, Lin et al. (1999, December 16) Sequence and Analysis of Chromosome 2 of the Plant Arabidopsis Thaliana. Nature Magazine \# 402 (6763).

\section{Figuras de referencia:}

Figura 1. Eduardo Kac, GFP Bunny. (2000)

Fuente:

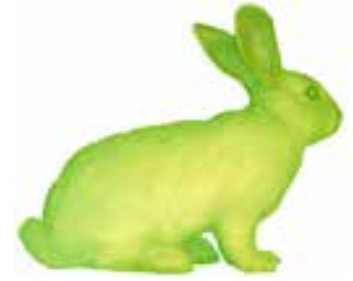

www.ekac.org/gfpbunny.html\#gfpbunnyanchor

Figura 2. Guiseppe Arcimboldo. Vertummus. (Ca. 1590)

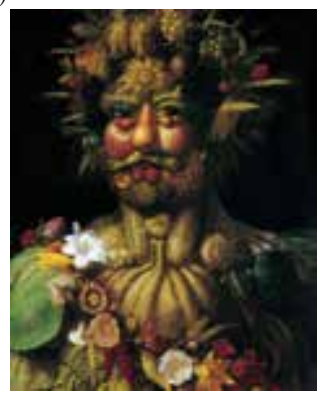

Fuente:

https://pinturasepocas.blogspot.com.co/2012/02/elemperador-rodolfo-ii-como-vertumno.html

Figura 3. El burro Lolo en la acción de pintar con la cola, la obra titulada Y el sol se quedó dormido sobre el Adriático. (1910)

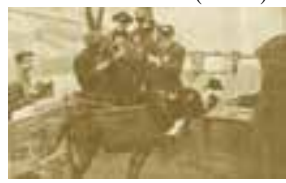

Fuente: https://bonjourparis.com/archives/cafe-lapinagile-montmartre-lolo-infamous-art-hoax/ 
Figura 4. La obra pintada por el burro Loló, titulada $\mathrm{Y}$ el sol se quedó dormido sobre el Adriático. (1910)

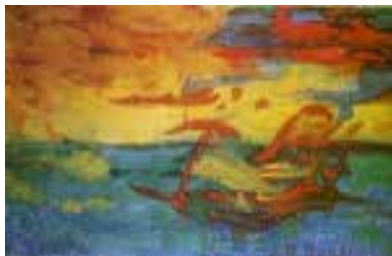

Fuente: https://bonjourparis.com/archives/cafe-lapinagile-montmartre-lolo-infamous-art-hoax/

Figura 5. Jussepe de Rivera. La Mujer Barbuda. (1631)

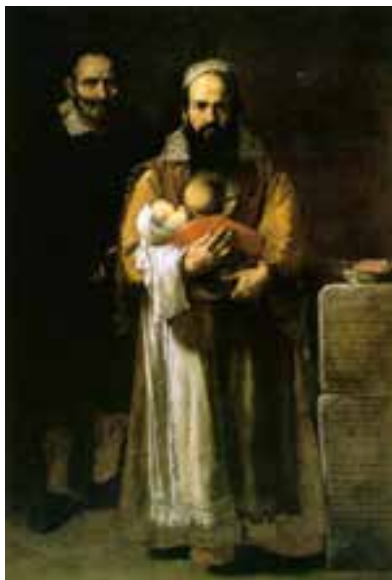

Fuente:

http://audioviator.blogspot.com.co/2012_11_01_archive.html

Figura 6. Lavinia Fontana. Retrato de una niña cubierta de pelo. (Ca. 1594-1595)

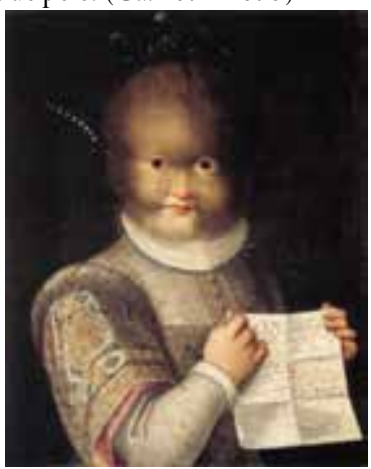

Fuente:

http://xsierrav.blogspot.com.co/2015/01/petrusgonzalvus-y-su-familia.html
Figura 7. Rene Magritte. La invención colectiva. (1935)

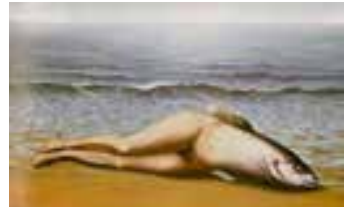

Fuente: https://xgfk12gms.wordpress.com/90-2/

Figura 8. Edward Steichen. Delphiniums. (1939)

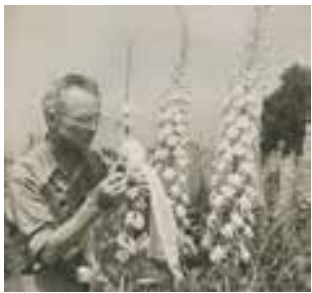

Fuente:

www.moma.org/explore/inside_out/2011/03/08/edward-steichen-archive-delphiniums-blue-and-whiteand-pink-too/

Figura 9. Me gusta América y a América le gusto yo. Performance. (1974)

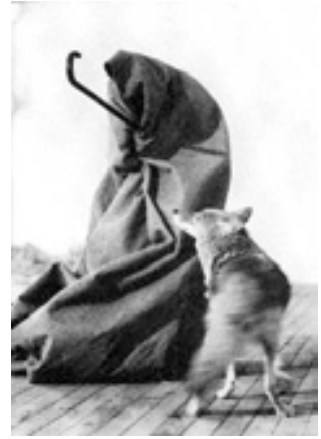

Fuente:

http://1.bp.blogspot.com/_kKtU4zdQy4g/RiLGsAUII wI/AAAAAAAAApQ/i9uW55TFLzQ/s1600-

h/fotojbeuysd.jpg

Figura 10. Louis Bec. Prolegomena. (1993)

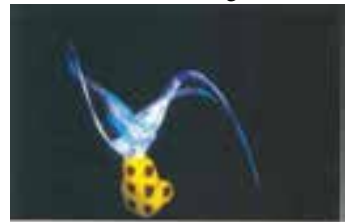

Fuente:

http://www.medienkunstnetz.de/works/prolegomena/ 